\title{
A Relevance Theory Prospective to the Twelfth Chapter of Cousin
}

\author{
Henry \\ Zheng $\mathrm{WU}^{1}$ \\ ${ }^{1}$ Department of Linguistics and Translation, City University of Hong Kong, Hong Kong, China \\ Correspondence: Zheng WU, Department of Linguistics and Translation, City University of Hong Kong, Hong \\ Kong, China. E-mail: zhengwu6-c@my.cityu.edu.hk
}

Received: July 18, 2020 Accepted: August 20, 2020 Online Published: August 28, 2020

doi:10.5539/ells.v10n3p105 URL: https://doi.org/10.5539/ells.v10n3p105

\begin{abstract}
Anthony Trollope, the British realist writer in the 19th century, writes Cousin Henry and this book is published in October 1879 without Chinese version yet. This work develops around the "will" dispute, presenting the conflict between the widespread social climate and the loft morals. With the guidance of the Relevance Theory, this report consists of the analysis and summary after the translation practice of the twelfth chapter of Cousin Henry, namely, Mr. Oven. This report adopts case-by-case analysis, based on the three principles of relevance theory, that is, ostensive-inferential communication, context and cognitive environment, optimal relevance. In the translation practice, it uses many translation methods, including addition method, domestication method, free translation method, segmenting method, adjusting-word-order method. These translation techniques are analyzed specifically when they are applied at the lexical and syntactic levels. By doing above-mentioned practices intend to enable the reader to get the optimal relevance and better the reading experience when he or she is reading the translation.
\end{abstract}

Keywords: Relevance Theory, translation strategy, processing effort, optimal relevance

\section{Introduction}

The material of this translation practice task is an English text, provided by the instructor, with the aim for translation practice of English to Chinese, through continuous revisions. The source text of the translation is the twelfth chapter of Cousin Henry, namely Mr. Owen. Cousin Henry is a novel written by Anthony Trollope, which was first published in 1879. The author, Anthony Trollope, is one of the classic realistic writers of 19th-century. The famous modern British writer Charles Percy Snow praised Trollope's work as "a peak of realism." His novels are like mirrors reflecting the social reality of his time, exposing and ridiculing the dark inside of the middle and upper classes of the Victorian era, while preaching the intent of moral dissemination. Trollope is famous for his "Chronicles of Barsetshire Series" (Smalley, 2013) and political parliamentary novels, which all depicted a true and vivid picture of life of Victorian British priests and the middle class. Anthony Trollope's book Cousin Henry continues his realistic style. What's more, this book has been called "one of his most experimental ones" among Trollope's shorter novels (Polhemus, 1966). The length of this source material amounts to 6719 words, meeting the standard of words requirement. Then no other person except me translate Cousin Henry until now. There are three main reasons for choosing this book as translation material. First, the background of this novel is the 19th century, the era of money worship, in which the author praised moral education. Then this novel also provided material for historical criticism in the related areas. Secondly, the main character in this novel is unlikely to be a hero, but a timid coward overwhelmed by guilt. Next, Trollope's handling of his characters and dilemmas are masterly in his insight and compassion. His craft in this novel abandons the previous and traditional expectation towards characters, while he describes the subverting expectations and dwells deeper on the psychology of characters. At last, it contains a large number of dialogues between characters, constructing a hypothetical context from the perspective of relevance theory, optimizing the readers' reading experience and enhancing readability. Personally, translating this material improves translation skills and strategies that have been acquired before, which can be actively combined with translation practices. At the same time, this practice can improve personal translation ability and enrich the knowledge about this novel, the author and the literature. 


\section{Theoretical Background}

This chapter is mainly about the introduction of the Relevance Theory, and how to apply the Relevance Theory to translation. The content of Relevance Theory is mainly developed from three principles, and its application in translation is based on the three parties, namely author, reader and translator.

The Relevance Theory is proposed by the French scholar Dan Sperber, and the British scholar Deirdre Wilson It is first put forward in the book Relevance: Communication and Cognition. The theory states that communication indeed is a process in which the speaker intends to explicit the information and the listener tries to recognize the intention behind the ostension through the inferential practice (Sperber \& Wilson, 1986). Under this theory, the listener relies on the explicit behavior of the speaker during this inferential practice, and then combines his or her own cognitive environment to make the corresponding cognitive efforts. By doing these practices generates contextual implication, and finally obtain the speaker's informative intention (Price \& Wilson, 2019). Before exploring insights into this theory, it is standard practice to discuss some principles in it. Language communication involves two modes, code mode and reasoning mode. Among them, the mode of cognition to inference process is basic while the switch process from the coding to the decoding is attached to the former process. According to Relevancy Theory, Sperber and Wilson regard communication as an ostensive-inferential process. "And the whole process of the conversational inference is subject to the constraints imposed by "the participants' beliefs and assumptions, including the beliefs the participants have about each other's beliefs and assumptions" (Gibbs Jr \& Tendahl, 2006). From the speaker's point of view, communication refers to a process in which he expresses his intentions without any mistake. From the perspective of the hearer, communication is an inferential process that the information and assumptions the speaker's communicative intention can be inferred.

According to Gutt's theory, translation is a process during which the translator interpretively resembles the source text while putting the optimal relevance and faithfulness into priority. When the translator is engaged in interpretive use to express information, his way to convey this information would be constrained by many considerations in order to optimally relevant. He would take efforts to construct the assumption, which the audience can reach the optimal relevance only through minimal processing effort. "Cognitive linguistics believes that grammar is symbolic in nature and it cannot be separated from semantic and phonological structures" (Deirdre Wilson, 2011). Considering that the translator merely serves as a person who has committed to interpretive work, the translator strongly expects to convey information in the suitable and appropriate way. In order to resemble to what the source remarks are talking about, he or she can be constrained by the meaning the translator himself want to express or even other derived meaning.

The major task of the translator is to convey the original information while commit to resemble the presumed material. This kind of the resemblance during translation process is to be "consistent with the presumption of optimal relevance" (Fraser, 1996). To some degree, the optimal resemblance under this circumstance seems to match well the idea of faithfulness. The faithfulness can be achieved by considering the contextual and textual factor. In the viewpoint of context, the translator is in pursuit for consistency with the principle of relevance through the audience's cognitive mind. From the text perspective, interpretive practice will make certain connection between the communicative intention of the translator and the intended interpretation of the source language.

Translation is also a kind of verbal communication, so the relevance theory regarding communication and cognition as its core has the strong explanatory force to translation. Deirdre Wilson's student, Ernst August Gutt, pioneers to apply relevance theory into the field of translation. He points out that translation, as a kind of communicative behavior, also relies on the relevance theory, especially when understanding the source language and choosing the reposed code. He hopes to explore a range of the translation phenomena and show how they can be accounted for in the relevance theoretic framework (Gutt, 1998). Domestic scholar (Goatly, 1994) also believes that relevance theory can explain the dialectical attribute of translation and can explain the capability of dialectically choosing during the process of translation. The translator bases on the ostensive behavior of the source language writer, then combines that with cognitive environment, makes cognitive efforts, produces contextual effects, and finally gains information from the source writer (Alves \& Gonçalves, 2003). In the second round, the translator is the speaker while the target audience is the listener. Translator and reader should try to find the relevance between the source language and the target language through paying proper processing effort, to achieve the coherence of the translated discourse. That's why the relevance theory plays a crucial role in the meanings of the source language and the translated language (Deidre Wilson, 2009). The target audience bases on the translator's ostensive behavior, then integrates with the cognitive context, paying cognitive efforts, generating contextual effects, and finally obtaining information which translator intends to express. 
However, at present, the research on literary relevance translation theory mainly focuses on the perspectives of authors, translators and, readers, instead of paying attention to the characters themselves in literary works. This paper starts from the inner focus of the characters in Cousin Henry, using the theory of relevance translation to achieve the self-rich contextual assumptions of the characters for seeking the best translation results. It also can serve as a viable tool for future research on the related translation theory applied to the literary characters themselves. The source text is selected from Chapters 12 and 13 of Cousin Henry, laying a solid foundation for future research on Cousin Henry itself or other studies on translation versions of Cousin Henry. The reader strikes a sound balance between "handling effort" and "context effect". Various translation strategies are adopted in different places of this material. By doing this, readers can choose to whether participate in the plot or not and can change independently from the subjective or objective perspective. This practice mobilizes the reader personal initiative and optimize the reader's reading experience. Therefore, this report pays special attention to the translation practice, applying the relevance theory and conducts a study on it. By translating this work, the translator believes it can make some contributions to literature-related translation theory and enrich the translation skills and guidance of Anthony Trollope's novels.

\section{Method}

Based on the research and interpretation of Cousin Henry during the pre-translation preparation, translation practice stage can be divided into three parts, including the first drafting, translation modifications, and proofreading.

\subsection{Analysis of the Source Text}

The literary works usually deal with the material in reality in the form of divergent thinking. The words in the work is its basic form of expression, and its core is usually expressed by the implicated meaning behind the words (Tendahl \& Gibbs Jr, 2008). Before translating the novel Cousin Henry, several steps are performed, like a preliminary reading, perusal reading and intensive reading of this novel in order to understand the content of the given material for a deeper and more accurate grasp.The novel is a literary genre that reflects the social life based on a complete storyline and concrete environment description or reflects social life through unfolding of the plot and complimenting by the environment (Nathania, Thren, \& Nathania, 2012).

\subsection{During Translation}

During the translation modifications period, the continuous process of resorting to the Chinese-English comparison is a better method to correct the first draft. The main standards for checking accuracy are listed as following, omission in translation and mistranslation, the coherent and smooth devices, and the wrong typos and punctuation (Lörscher, 2005). Other factors point to whether the terminology, person name, and proper noun are all translated consistently in the translation. What's more, some difficulties and confusion points were also marked. The next step was to find typical examples and analyze them under the guidance of relevance theory. All these examples were presented in the following section, namely case study, being said the essential part of this practice report.

\subsection{Post-Translation Activities}

In terms of the translated text's quality, the readers first are supposed to affirm that the translated version conformed to the principle of "faithfulness". They also tend to indicate that the translated version basically followed the principles of the relevance theory in terms of word selection, sentence structure, and textual coherence. However, further adjustments can be made to some certain words and phrases, which enables the translated to be in line with Chinese expression while avoid the occurrence of translationese. As for the expressive style, the translated one was consistent with the language style of the source material. Meanwhile the reader's cognitive level and reading capability were also considered, which was worthy of recognition. After translation, the problems that emerged in the translated version are reflected as it is a standard practice to improve my translation skills.

\section{Case Study}

Under the guidance of Relevance Theory, the writer comprehensively taking the original context, the context of the target language, the translator's leading role and other factors all are taken into account in the process of translation practice. Then it is ought to analyze the twelfth chapter in Cousin Henry at the lexical, sentence and discourse level, and propose corresponding translation methods and techniques to these places. 


\subsection{Lexical Level}

[1]

SL: To go and die and have done with it, if that might be possible, was the panacea of her present troubles most commonly present to her mind.

\section{TL：如果可以的話，解決一直困擾她諸多麻煩的萬能藥是，下定決心去死一了百了。}

Due to differences lying in Chinese and English habits and thinking patterns respectively, the order of words in a sentence or the orders of sentences in a sentence group need to be adjusted in order to conform to the thinking habit of Chinese reader. By doing this, the reader can understand the meaning of the source text with less processing effort. If no adjustment is made, the translated version will be unreasonable, unintelligible, illogic, and even less likely to convey the meaning of the original text. Therefore, it is of importance to adjust the order of the sentences to suit the reader's language-using habit. This sentence uses the infinitive as its subject, and the infinitive is composed of three verbs juxtaposed together. Although these three verbs are connected with the word "and", they imply a splicing relationship. The word "Go" is an action, then followed by the word "die", and the result caused by these two words is "have done with".

In Chinese expression, it is not necessary to use obvious sequential or causal signs. When Chinese reader does some reading, he will naturally cognize the order of verbs through combining semantic with self-assumptions. Thus, these three words will be translated literally. As a parenthesis, the phrase "If that might be possible" is translated when it takes sentence meaning and sentence fluency into considerations, which means that it should be placed at the beginning or end of the sentence when translated. If it still is put in the original position in the source text, it will make the reader feel awkward when reading, affecting his fluent feeling (Wang, 2014). At the same time, the reader also has to work hard to deal with the position of this parenthesis. In English, the main clause is the main part, which is usually placed at the beginning of the sentence, that it is put the most important part in front. While the Chinese one is generally placed according to the logical and chronological order, and the main part is placed at the end of the sentence to form the posterior center. The word "panacea" is translated into “萬能藥”, which can correspond to the plural concept of "troubles". The panacea can be used to to solve these troubles regardless of the amount of troubles. In addition, the panacea is a cultural image that is familiar to Chinese reader. The author's intention is successfully passed on to the targeted reader, the Chinese one, so that he get enough contextual assumptions and achieve optimal relevance.

[2]

SL: He, no doubt, would be generous enough to renew his offer.

TL: 歐文先生不確定伊莎貝爾是否還會拒絕求婚, 但他仍會不計前嫌向她提出求婚。

The phrase "no doubt" acts as is attributive part, then completing it being "he is no doubt". The specific content of "no doubt" is that "she would refuse his proposal", where the content of the attributive is directly defined. Meanwhile, the abtrast word "offer" when combined with the word "renew", it clearly represents that it isnot the first time to propose a marriage proposal. So when translating the second half of the sentence, the translator is supposed to explain the word "offer" in detail, taking the consideration of the prefix of "re". This does not require the reader to use his self-understanding to dissect the meanings and real idea implicating in this expression and processing effort also can be minimized. In addition, the word "generous" is translated into the idiom “不計前嫌”, which is familiar to the Chinese reader and is also easy for them to understand the meaning. The translator can try to find a new word on the basis of the corresponding semantic or meaning between the original word and the translated one. When finding this kind of the translated word, the translator needs to creatively translate the semantic meaning of the original word, just like the adjectives word "generous" mentioned -above, representing very abstract conception. A translator needs to give answer of degree, to meet the reader's reading assumed expectations.

[3]

SL: I don't see how you could have the face to refuse the money, and then to eat his bread.

TL: 我不知道你怎麼能拒絕歐文先生的錢, 但卻依賴著歐文先生過日子。

The word "bread" in the phrase "eat his bread" in this sentence, shares the same meaning with the word "bread" in "earn one's bread". Both "bread" represents metaphorical meaning. This kind of metaphor belongs to different figures conveying the semantic equivalents in Chinese and English language. To be more specific, there existing difference between metaphor and literal meaning in the direct expression. The concept is the result of the brain's thinking. Sperber and Wilson believe that "the information of certain conception stored in memory can be 
divided into three types: logic, encyclopedia, vocabulary" (Deirdre Wilson \& Sperber, 2002). Logic refers to the logical location of the concept, encyclopedia the context and background information of the concept, and vocabulary the pronunciation or grammatical category of the word. The cognitive context isnot pre-set in the process of understanding, but the result of constantly choosing in the process of understanding the author. The process of choice is not casual, subjected to the reader's encyclopedic memory-structure and the mental activity engaged in this activity. When the reader see the word "bread", he usually considers these contextual assumptions. These assumptions contributes the reader better understand this context and gain implicating meaning. The spread of the "bread" concept leads to cognitive effect is used as the extended meaning of the "bread", allowing the reader to complete the optimal expectation toward this passage. The focus of the reader will be placed on the adjective word, and adverbial only serves to supplement. Translating in that way not only effectively conveys the information intention, but also simplifies the original text information. What's more, it also highlights the key information and achieves the optimal relevance.

[4]

SL: What! to eat his bread after refusing him mine when it was believed to be so plentiful!

TL: 什麼! 當我擁有繼承權可以繼承豐厚的遺產時, 拒絕歐文先生的求婚。而現在卻又想依靠他過日子。

In the process of translation, the translator to great extent grasps the language characteristic of the source text. The word "mine" is the abbreviation of my bread. When translating "mine", the placing the reference method should be used, so as to put the original pronoun in the source text to the Chinese corresponding reference, which is My (Isabel's) inheritance right. This sentence expresses that Isabel at first had the inheritance right inheriting a large amount of property, so Mr. Owen's proposal was rejected. If the translator does not do the reference restoration process, and literally translates it into “麵包”, which not only does not express the contextual effect, but also makes the audience misunderstand and fail to achieve the optimal relevance. "The translator's responsibility is to strive to match the intention of the source author with the expectation of the target reader." (Yushan \& Rui, 2018). If the translation deviates from the context, then when understanding the reader's processing effort will be increased and the contextual effect obtained will be reduced. Therefore, the relevance of the translation is reduced, which ultimately affects successful communication, presenting a sound translation. Meanwhile the translated vision “麵包” echoes with the word "bread" in the sentence “I don't see how you can have the face to refuse the money, and then to eat his bread", which allows reader to natural associate with the above sentence. Linking these two sentences together helps the reader get a better understanding of this context.

\subsection{Sentence Level}

[5]

SL: But I suppose you acknowledge your right to be as good as your word?

$\mathrm{TL}$ : 但是, 我認為你應該說到做到吧。

This sentence corresponds to above sentence, namely, Isabel said, "I do not acknowledge papa's right or yours to press me to marry any man". The word "acknowledges" and "right" are repeated in the same meaning. In the last sentence, Isabel complained that she does not think Dad and you (mother) have the right decide whom she is going to marry. Moreover, this sentence is to dismiss Isabel's last sentence, so it carries with a slight irony. If the literal translation is applied, that is, “我認為你應該承認你的權利和你說的話一樣好”, the translationese is revealed. Here, domestication translation should be used to gain the familiar expression that the Chinese reader is usually used, so that the translated version can be brought closer to the authentic language. Doing this means that "merely translating their pragmatic meanings and communicative intentions is aimed to reduce the reading burden of reader, and achieve better inter-lingual and code communication" (Huang \& Yang, 2014). “說到做到” is a phrase at hand in ordinary life, and it is very familiar to Chinese reader. At the first glance, the reader knows the meaning that the author wants to express, inclining to having a slightly criticized color. The domestication translation method can make the translation conform to the Chinese cultural conception and social cultural background as well as the reader's social psychology. Therefore, there exists the optimal relevance between the translation and the reader's cognitive environment, and the translation is more acceptable.

\section{[6]}

SL: and then he could advise her as to that project of being governess, housemaid, schoolmistress, or what not.

TL: 但他可以, 就做家庭教師、女傭、女教師, 或者其他別的什麼她自己想做的事, 提出建議。

If there place only a few translated positions, it will seem very awkward. In addition, this makes the reader wonder why the author wants to cite these positions and why Mr. Owen makes suggestions on these positions. 
Thus, the translator should use the addition method to properly interpret and supplement the vague places in the source text in order to eliminate the confusion of the audience and save effort of the guess. It is necessary to provide reader with a number of optional factors that can be selected to achieve the optimal relevance, so that it is possible to ensure "the proper of the reader's reasoning" (Ren \& Li, 2015). Here, all these adding things are what Isabel herself likes to do, so the examples given here acts as just the examples, not being inexplicable. The additional translation can express the hidden element or content in the source text by using obvious expressions, especially the content of the relevant background information. The extent of the addition translation should be kept to a minimum, which means that there cannot exist much content being translated, otherwise the translation will be interpreted as whole. Therefore, in translation process, it is necessary to flexibly translate according to the Chinese expression habit and linguistic features, to accurately and faithfully express the information of the English text. The part of addition not only completes the information, but also facilitates the translator to complete a vivid interpretation of the role.

\subsection{Discourse Level}

[7]

SL: Afterwards, when she had believed that there would be a sum of money coming to her from her uncle's will, there had been room for possible doubt.

TL: 後來, 當她確信依照她叔叔的遺囑, 她將得到 400 英鎊時, 那拒絕歐文先生求婚這件事就有待商榷

The phrase "a sum of money" is supposed to be more specific. The literal meaning here represents only a sum of money, but it on earth means the inheriting money from the uncle's will, or means only a small amount of money $\$ 400$, which is ambiguous. Each reader holds different perception towards the concept of “一筆”. The result is that the meaning of "a sum of" would have different references, and it will cause the reader's reading confusion. The specific amount is directly indicated, so that the target reader can understand without making unnecessary processing efforts. Similarly, if the word "doubt" is translated into “懷疑”, the former part of this sentence cannot share the same tone with its later part, resulting in the meaning of this sentence being unexpressive. The reader has to pay more efforts to work harder by reviewing the story line of the previous chapters. At this time, the translator needs to extend or expand the content of the source text appropriately to avoid being disturbed by the literal meaning of words. As a result, the deep meaning of the source text can be better understood, and the author and the reader can achieve more effective indirect communication intentions.

[8]

SL: There would have been much against it even then, because she had refused him when she had been a grand lady.

TL: 先前伊莎貝爾成為有錢的繼承者時, 她拒絕了歐文先生的求婚。所以她還不能確定是不是要嫁給歐 文先生。

The Re-arrangement of Information Unit (RAIU) is one of translation methods and language expressions, which translators can choose. The RAIU, also known as the adjustment of words sequence, refers to a method of readjusting the order of components or words in a sentence. The source text arranged vocabularies in certain form then this sequence changed into another vocabulary is a case in point. The cognitive context of the source-language reader and that of target-language counterpart is different, and their focus is also different. What's more, Chinese and English language have different characteristics in terms of thinking mode and language expression habit. Therefore, it is necessary to use the RAIU method for translation in order to make the translation clearer and more accurate, which can achieve the effect of the optimal relevance. In English, sentence structure is the cause followed by effect, while sentence structure in Chinese is opposite. In this sentence, the word order should be adjusted for translating the reason first. If the translator chooses the method of literal translation to translate in the original sequence, it would not conform to the language habit of target language. Consequently, it will not enable the reader to obtain the same experience of contextual assumption, which equal to the English context. Thus, they could not understand the information and communication intention that the author tries to convey. The translated version by this way is unsuccessful. At the same time, the phrase "a grand lady” originally referred to “貴婦人”, but at that time, the Isabel is unmarried and could not be called as “婦人”. In addition, the modified adjective word "grand" should be translated closely to the meaning of money. This refers to the situation when Isabel became the heir of Lanfel. The free translation is applied here, and the reader does not need to think about the meaning of this word but can naturally go on reading it. Meanwhile, it also echoes the previous mentioned her becoming the inheritor of Lanfel. The translation here not only considers the 
reader's cognitive environment, but also the phrase can be translated concisely and clearly. Thus, the translator adopts free translation, so that the readers can understand the meanings of the whole text at a glance and obtain sufficient "contextual effects" (Li, Qian, \& Zhang, 2018). The main role of the adaptation method is to achieve a high degree of agreement between the author's intention and the reader's expectation. In the process of translation, the translator will encounter many problems, as Chinese sentences and English ones have different structure respectively. The sequence of long sentences or short sentences in the source text is difficult to be consistent with the targeted text after translation. The translator will be required to re-organize and decompose these sentences when they are translated based on time and logical order in Chinese, to achieve the purpose of a sound translated version.

[9]

SL: "Certainly not," said Isabel; "neither that nor yet the position which Mr. Owen will perhaps offer me again."

TL: “當然不接受”，伊莎貝爾說，“也不會接受歐文先生可能再次提出的求婚”。

The pronoun "that" refers to the mentioned above "accept the money from your cousin," The conjunction word "neither...nor..." connects two negative components, indicating that both are negated. The word "position" is an abstract concept, and its verb in this sentence is still the verb "accept" as in the above sentence, showing two paralleling negative objectives. The linguistic communication includes implicit and explicit meanings, while the relevance theory emphasizes the translational mode, ostensive-inferential pattern. Due to the obvious differences between cognitive environment of the author and that of the reader, it is difficult for the reader to derive implied communicative intention implicating from semantic content in the source text. Thus, the translator must transform such implied meaning into explicit meanings. In this sentence, if the word "position" is selected literal meaning, it will make the reader bewildered. Through this addition method, the word "position" will be directly expressed without being restricted to word-by-word literal translation, emphasizing the equivalence of the translation, thus providing the best contextual effect for the reader while avoiding unnecessary efforts.

\section{Conclusion}

In this translation practice, the translator studies Cousin Henry from perspective of the Relevance Theory. From above case study, this paper pays special attention to the lexical and syntax level starting from three aspects in pursuit of the better translation. Through listing a number of examples in translation practice, this report adopts various translation strategies for different lexical or syntax in the contexts, to achieve the contextual effect and the optimal relevance. Moreover, through the research on colloquial remarks, the literal translation strategy is given first when considering the characteristics of the dialogue. While the target reader, mainly the Chinese reader, fails to obtain in the contextual assumption the same as the source-language reader, free translation and other translation strategies are more likely to be used. Meanwhile, the translator is supposed to ensure that the context effort gained by the reader is equal to the context structured by the author when taking three principles all into consideration. However, if the contextual assumption provided by the translated version is even beyond that of the original text in the source text. This may seem not like a good thing, given the fact that the pleasure of reading literary work lies in that the reader continues to make cognitive effort, gives subjective initiative to full play, and enjoys the happiness brought by the inferential process. The translator cannot deprive the target reader of that kind of experience. Therefore, it is not advisable that the relevance of the translation is lower or higher than the relevance of the source text. Of course, achieving that kind of the relevance is only an ideal state, which is the goal, pursued by the translator. In the actual translation process, the translator is only constantly seeking a dynamic balance between the two sides. Because of the lack of time, own knowledge, and enough reference materials, the source text fails to be analyzed from a deeper level. In addition, the practice of analyzing the listed examples and these opinions based on the listed examples may not be mature, but it is indeed lied on my current knowledge. Therefore, in the future, commitment will be made to studying these deficiencies.

\section{Acknowledgments}

I would like to express my gratitude to my supervisor, Dr. Zheng Hongsheng, for his constructive opinions and suggestions on the research's direction of this report. During the writing process, Dr. Zheng had committed to facilitating and assisting me when I encountered lots of difficulties and doubts, and he put forward much enlightening advice for me. Looking back overall process, Dr. Zheng, with patience, invested a lot of effort and energy, considering that he gave me painstaking guidance and help, as well as selflessly modified and improved this report. So, I would like to give my sincere gratitude to his help and care.

\section{References}

Alves, F., \& Gonçalves, J. L. V. (2003). A Relevance Theory approach to the investigation of inferential 
processes. Triangulating Translation: Perspectives in Process Oriented Research, 45, 3. https://doi.org/10.1075/btl.45.04alv

Fraser, J. (1996). The translator investigated: learning from translation process analysis. The Translator, 2(1), 65-79. https://doi.org/10.1080/13556509.1996.10798964

Gibbs Jr, R. W., \& Tendahl, M. (2006). Cognitive effort and effects in metaphor comprehension: Relevance theory and psycholinguistics. Mind \& Language, 21(3), 379-403. https://doi.org/10.1111/j.1468-0017.2006.00283.x

Goatly, A. (1994). Register and the redemption of relevance theory: the case of metaphor. Pragmatics, 4(2), 139-181. https://doi.org/10.1075/prag.4.2.05goa

Gutt, E.-A. (1998). Pragmatic aspects of translation: Some relevance-theory observations. The Pragmatics of Translation, 41-53.

Huang, H., \& Yang, X. (2014). Metaphor interpretation and motivation in relevance theory. Journal of Pragmatics, 60, 266-273. https://doi.org/10.1016/j.pragma.2013.08.015

Li, W., Qian, J., \& Zhang, K. (2018). EC Translation of Medicine-Health Texts: Optimal Relevance. Open Journal of Modern Linguistics, 8(6), 294-303. https://doi.org/10.4236/ojml.2018.86023

Lörscher, W. (2005). The translation process: Methods and problems of its investigation. Meta: Translators' Journal, 50(2), 597-608. https://doi.org/10.7202/011003ar

Nathania, N., Thren, A., Nathania, N., \& Andrew, T. (2012). Translation Techniques Used to Translate Harry Potter and the Deathly Hallow Novel. Faculty of Language \& Literature Satya Wacana Christian University.

Polhemus, R. M. (1966). Cousin Henry: Trollope's Note from Underground. Nineteenth-Century Fiction, 20(4), 385-389. https://doi.org/10.2307/2932669

Price, H., \& Wilson, J. (2019). Relevance theory and metaphor: An analysis of Tom Waits' 'Emotional Weather Report'. Language and Literature, 28(1), 61-81. https://doi.org/10.1177/0963947019827074

Ren, J., \& Li, Y. (2015). A complementary perspective of conceptual blending theory and relevance theory on metaphor interpretation. Theory and Practice in Language Studies, 5(10), 2091-2096. https://doi.org/10.17507/tpls.0510.16

Smalley, D. (2013). Anthony Trollope: The Critical Heritage. Routledge. https://doi.org/10.4324/9781315004563

Sperber, D., \& Wilson, D. (1986). Relevance: Communication and cognition (Vol. 142). Harvard University Press Cambridge, MA.

Tendahl, M., \& Gibbs Jr, R. W. (2008). Complementary perspectives on metaphor: Cognitive linguistics and relevance theory. Journal of Pragmatics, 40(11), 1823-1864. https://doi.org/10.1016/j.pragma.2008.02.001

Wang, F. (2014). A model of translation of politeness based on relevance theory. Open Journal of Social Sciences, 2(09), 270. https://doi.org/10.4236/jss.2014.29045

Wilson, D. (2009). Parallels and differences in the treatment of metaphor in relevance theory and cognitive linguistics. Studies in Pragmatics, 11, 42-60. https://doi.org/10.1515/iprg.2011.009

Wilson, D. (2011). Parallels and differences in the treatment of metaphor in relevance theory and cognitive linguistics. Intercultural Pragmatics, 8(2), 177-196. https://doi.org/10.1515/iprg.2011.009

Wilson, D., \& Sperber, D. (2002). Relevance theory. In Blackwell.

Yushan, Z., \& Rui, C. (2018). Translation of Onomatopoeia Words in The Republic of Wine from the Perspective of Relevance Theory. Studies in Literature and Language, 17(3), 18-21. http://doi.org.10.3968/10715

\section{Copyrights}

Copyright for this article is retained by the author, with first publication rights granted to the journal.

This is an open-access article distributed under the terms and conditions of the Creative Commons Attribution license (http://creativecommons.org/licenses/by/4.0/). 